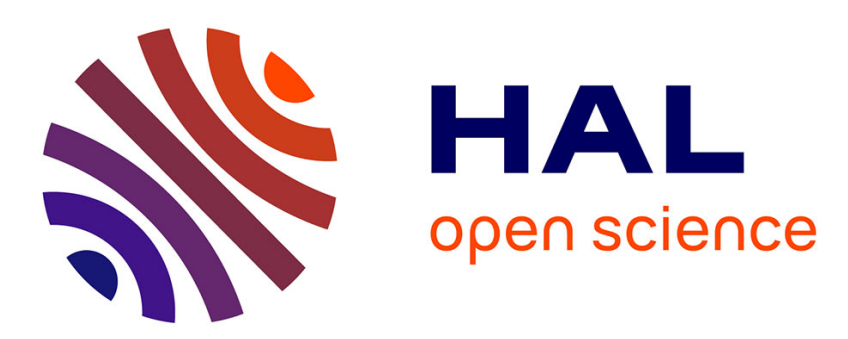

\title{
A theoretical investigation of water-solute interactions: from facial parallel to guest-host structures
}

\author{
Cairedine Kalai, Emilie-Laure Zins, Mohammad Esmaïl Alikhani
}

\section{To cite this version:}

Cairedine Kalai, Emilie-Laure Zins, Mohammad Esmail Alikhani. A theoretical investigation of water-solute interactions: from facial parallel to guest-host structures. Theoretical Chemistry Accounts: Theory, Computation, and Modeling, 2017, 136 (4), pp.48. 10.1007/s00214-017-2074-2 . hal-01497694

\section{HAL Id: hal-01497694 \\ https://hal.sorbonne-universite.fr/hal-01497694}

Submitted on 29 Mar 2017

HAL is a multi-disciplinary open access archive for the deposit and dissemination of scientific research documents, whether they are published or not. The documents may come from teaching and research institutions in France or abroad, or from public or private research centers.
L'archive ouverte pluridisciplinaire HAL, est destinée au dépôt et à la diffusion de documents scientifiques de niveau recherche, publiés ou non, émanant des établissements d'enseignement et de recherche français ou étrangers, des laboratoires publics ou privés. 
A theoretical investigation of water-solute interactions: From facial parallel to guest-host structures

Cairedine Kalai, Emilie-Laure Zins, and Mohammad Esmaïl Alikhani *

${ }^{*}[*]$ C. Kalai, Dr. E.L. Zins, Pr M.E. Alikhani

Sorbonne Universités, UPMC Univ. Paris 06, MONARIS, UMR 8233,

Université Pierre et Marie Curie,

4 Place Jussieu, Case Courrier 49, 75252 Paris Cedex 05, France

CNRS, MONARIS, UMR 8233,

Université Pierre et Marie Curie,

4 Place Jussieu, Case Courrier 49, 75252 Paris Cedex 05, France

Email: esmail.alikhani@upmc.fr 
Keywords: noncovalent interactions, exohedral complex, endohedral complex, molecular electrostatic potential (MESP), Quantum Theory of Atoms in Molecules (QTAIM)

\begin{abstract}
Encapsulation of small (bio-)organic molecules within water cages is governed by a subtle equilibrium between water-water and water-solute interactions. The competition between the formation of exohedral and endohedral complexes is investigated. The first step prior to a theoretical characterization of interactions involved in such complexes lies in the judicious choice of a level of theory. The $\beta$-propiolactone (BPL), a solute for which the micro-hydration was recently characterized by means of high resolution microwave spectroscopy (Angew. Chem. 2015, 127, 993), was selected for the present study, and a calibration step is carried out. It is shown that the dispersion-corrected density functional theory (DFT-D) suitably reproduce the geometric, energetic and spectroscopic features of the BPL: $\left(\mathrm{H}_{2} \mathrm{O}\right)_{1-5}$ complexes. The experimentally-deduced structures of the BPL: $\left(\mathrm{H}_{2} \mathrm{O}\right)_{4,5}$ species are fully understood in terms of the maximization of interactions between complementary sites in the MESPs. DFTD calculations followed by the topological analysis within the Quantum Theory of Atoms in Molecules framework have shown that the solute could efficiently interact with $\left(\mathrm{H}_{2} \mathrm{O}\right)_{6,10}$ clusters in a similar manner that the $\left(\mathrm{H}_{2} \mathrm{O}\right)_{4,5}$ clusters do. The interaction of the solute with two larger water clusters is further investigated. The exohedral and endohedral BPL: $\left(\mathrm{H}_{2} \mathrm{O}\right)_{20}$ isomers are close in energy with each other, whereas the formation of an inclusion complex is energetically more favored than the facial interaction in the case of the BPL: $\left(\mathrm{H}_{2} \mathrm{O}\right)_{24}$ cluster. The topological analysis suggests that the substantial energetic stability is due to interactions between the solute and almost all oxygen atoms of the water cage.
\end{abstract}




\section{Introduction}

Due to their ubiquitous implications in almost all chemical fields, the hydration processes of organic molecules have consistently been the topic of experimental and theoretical investigations. Water-water and water-solute interactions compete and efficiently complement each other in important equilibria [1-9].

For instance, hydrated species in which small water clusters are attached to a solute, were characterized for several systems $[2,10,11,12]$. In a combined force-field and DFT approach, a clear segregation between the water molecules and the solute in hydrated complexes of 2aminooxazole containing one to twenty water molecules has been reported by Calvo et al. [13] The authors underlined that the solute-solvent hydrogen bonding strength is weaker than the water-water ones, leading to a negligible distortion of the water cluster up to 2aminooxazole: $\left(\mathrm{H}_{2} \mathrm{O}\right)_{15}$ cluster. For complexes containing more water molecules, the solutesolvent interaction competes with the solvent-solvent interaction. Xantheas et al. recently reinvestigated the Benzene: $\left(\mathrm{H}_{2} \mathrm{O}\right)_{8}$ complex in a combined DFT and post-Hartree-Fock study [14]. They underlined that unlike to the popular B3LYP functional the dispersion-corrected functional $(\omega \mathrm{B} 97-\mathrm{XD})$ is able to satisfactorily describe the Benzene: $\left(\mathrm{H}_{2} \mathrm{O}\right)_{8}$ complex interaction. They identified five isomers in which a cubic water octamer is attached to the aromatic ring, with similar energetic stability $\left(\Delta_{\mathrm{E}}<4 \mathrm{~kJ} / \mathrm{mol}\right.$ at the MP2/aVTZ//MP2/aVDZ level of theory). They also showed that each isomer involves a cubic water octamer almost in facial parallel interaction with the aromatic ring.

Furthermore, the formation of inclusion complexes in clathrate hydrates also underline the paramount importance of the complementary water-water and water-solute interaction. For instance it was shown at a molecular level that methane is efficiently encapsulated in a $\left(\mathrm{H}_{2} \mathrm{O}\right)_{20}$ cage, whereas larger $\left(\mathrm{H}_{2} \mathrm{O}\right)_{24,28}$ cages lead to more stable complexes when $\mathrm{SF}_{6}$ is the guest molecule [15]. Smaller guest species such as rare gases, diatomic or triatomic molecules may be efficiently trapped in the $\left(\mathrm{H}_{2} \mathrm{O}\right)_{20}$ cage with the concomitant formation of multiple water-solute interactions [16], characterized by bond critical points (BCPs) in the Quantum Theory of Atoms in Molecules (QTAIM) approach [17]. It was found that such small guest molecules do not lead to major distortion of the water cage. Some guest molecules however may dramatically affect water-water interactions, leading to so-called guest-induced Bjerrum defects [18].

A qualitative and quantitative understanding of interactions involved in the formation of endohedral and exohedral complexes at a molecular scale would help in understanding various processes such as hydration of small (bio-)organic molecules, and clathrate formation. Endohedral complexes refer to the formation of inclusion compounds, whereas in exohedral complexes, the solute lies outside the water cluster. The present study is concerned with the mutual competition between endohedral and exohedral complexes.

A simple, powerful and quick method based on a measurable physical property of molecules and clusters was used to identify favorable interactions between two species: the molecular electrostatic potential (MESP) [2,19-27]. When investigating non-covalent interactions, studies based on the MESP analysis are mainly of two types: 
$>$ explanatory approach: A quantitative analysis of the isolated monomers MESPs may lead to the identification of electron-rich and electron-deficient regions ( $\sigma$-holes or $\pi$ holes for instance). The identification of such local features provides a useful tool for interpreting various non-covalent interactions such as tetrel, chalchogen, halogen and hydrogen bondings, as demonstrated by Politzer, Murray et al. [20-22];

$>$ predictive approach. Among other approaches [28,29], we can mention the electrostatic potential for intermolecular complexes (EPIC) model of Pundlik et al.[30]. This model allows the study of weakly bond complexes between two species based on the calculation of the electrostatic interaction energy. It relies on the analysis of critical points of the electrostatic potential on isolated monomers, the MESP study of one species and the MESP-driven point-charges of the other species. This model has been applied to the characterization of various complexes. [31]

Herein another predictive approach is proposed:

(i) As a starting point, we investigate the possibility of a simple, qualitative analysis of the MESP for both isolated solute $(S)$ and solvent clusters $\left(W_{n}\right)$ for proposing $S: W_{n}$ guess geometrical structures. Throughout the present work, the MESP analysis was used to unravel so-called "electron-rich" and "electron-deficient" regions. We should mention that such features only refer to surface properties, and not to volumes. The existence of 3D MESP maxima was indeed ruled out by Pathak et al. in the 1990's [32]. Initial geometries of complexes are built up considering the fact that electronrich regions of the solute will be attracted towards an electron-deficient region of water clusters, and conversely. A visual inspection of the MESP of both isolated partners enables us to suggest several possible geometries which maximize the number of complementary MESP regions. Such approach has been already successfully applied to other cases. [11,33]

$>$ (ii) In a second step, these structures are fully optimized using ab initio or DFT approaches.

$>$ (iii) Finally, water-solute interactions are analyzed by means of the QTAIM topological tool applied on the optimized structures.

For such a study, the judicious choice of a level of theory for a consistent geometric and electronic description of complexes is an obvious and needed prerequisite. It was shown that dispersion-corrected density functionals may suitably describe such complexes provided that a calibration step is carried out, either with respect to the experimental data or to the results coming from high-level theoretical calculations [14,16,34].

Recently Alonso et al. investigated the interaction between the $\beta$-propiolactone (BPL) and up to five water molecules [35]. A clear segregation between the water molecules and the solute was experimentally observed for the BPL: $\left(\mathrm{H}_{2} \mathrm{O}\right)_{4,5}$ complexes. This system was thus chosen for our study.

The paper is structured as follows: First of all, the choice of an exchange-correlation functional able to well reproduce energetic, geometric and electric properties of the water BPL interaction in the BPL: $\left(\mathrm{H}_{2} \mathrm{O}\right)_{\mathrm{n}}(\mathrm{n}=1-4)$ cluster, is detailed. To further shed some light on the interactions involved in the formation of facial-parallel structures deduced from 
experimental data for the BPL: $\left(\mathrm{H}_{2} \mathrm{O}\right)_{4,5}$ clusters, a characterization based on the molecular electrostatic potential (MESP) and the Quantum Theory of Atoms in Molecules (QTAIM) topological tools is presented $[17,36]$. Stable structures involving the formation of similar water-solute interactions for the BPL: $\left(\mathrm{H}_{2} \mathrm{O}\right)_{\mathrm{n}}(\mathrm{n}=6,10)$ clusters are then identified. In the last part, larger clusters involving 20 and 24 water molecules are studied. Two small prototypical $5^{12}$ and $5^{12} 6^{2}$ water cages constituting elementary assemblies of some water clathrates were investigated. A particular attention is devoted to the transition from a facial parallel structure to the endohedral compound and to their mutual competition, until the completion of the first hydration shell around the BPL molecule.

\section{Method calibration}

All the geometry optimizations were carried out using the Gaussian 09 Rev D.01 software [37]. The D2 and D3 versions of the dispersion-corrected density functional theory within the framework of the Becke-Johnson damping function [3,38] further denoted as GD2 and GD3BJ, were employed. The following functionals were selected: B3LYP-GD3BJ, [3,10,39] B2PLYP [40], B2PLYP-GD2, B2PLYP-GD3BJ, $\omega$ B97XD and LC- $\omega$ PBE-GD3BJ [41,42,43] in combination with the Pople's 6-31++G(d,p), 6-311++G(d,p), 6-311++G(2d,2p), and the Dunning's aug-cc-pVDZ and aug-cc-pVTZ basis sets, further referred to as Pop1, Pop2, Pop3, aVDZ and aVTZ, respectively. The CCSD(T)-F12/aVDZ method was selected as a reference method, and MP2/aVDZ as well as MP2/aVTZ calculations were also carried out. Dipole moments have been calculated with the "Density=Current" instruction for MP2, CCSD/aVDZ//CCSD(T)-F12/aVDZ (single-point with CCSD/ aVDZ at the CCSD(T)-F12/ aVDZ optimized geometry) and B2PLYP calculations. The molecular electrostatic potentials and the Quantum Theory of Atoms In Molecules (QTAIM) analyses were carried out using the AIMAll [44] software, for the identification of hydrogen bonding and non-covalent interactions [17].

The mono-hydrated BPL: $\left(\mathrm{H}_{2} \mathrm{O}\right)$ complex was chosen as a probe to evaluate the accuracy of the exchange-correlation functionals in describing the non-covalent interaction between water and BPL. The most relevant geometrical and energetic characteristics calculated with the 17 selected levels of theory for the BPL: $\left(\mathrm{H}_{2} \mathrm{O}\right)$ complex are gathered in the Table 1 . The binding energy was calculated as follows: $D_{e}=E_{\text {comp }}-\left(E_{1}+E_{2}\right)$, where $E_{\text {comp }}$ is the total energy of the $\mathrm{H}$-bonded complex and $\mathrm{E}_{1}$ and $\mathrm{E}_{2}$ are the total energies of the optimized free units (BPL molecule and water cluster).

The experimental rotational constants ${ }^{2}$ are described with a relative error (RE) less than $5 \%$ at all the chosen DFT levels. The experimental values $\left(\mu_{\mathrm{a}}, \mu_{\mathrm{b}}\right.$ and $\left.\mu_{\text {tot }}\right)$ of the dipole moments are accurately reproduced (RE $\leq 5 \%$ ) only at three levels of theory: B2PLYP-D/Pop3, B2PLYPGD3BJ/Pop2, and LC-wPBE-GD3BJ/Pop2.

Eight levels of theory accurately reproduce the binding and complexation energies calculated at the $\operatorname{CCSD}(\mathrm{T})$ level with a $\mathrm{RE} \leq 5 \%$ : the B2PLYP-D/Pop2, B2PLYP-D/Pop3, $\omega$ B97XD/Pop2, $\omega$ B97XD/Pop3, LC- $\omega$ PBE-GD3BJ/Pop2, LC- $\omega$ PBE-GD3BJ/Pop3, B3LYPGD3BJ/ Pop2 and B3LYP-GD3BJ/Pop3 levels. Furthermore, the MP2/aVDZ and MP2/aVTZ 
levels suitably describe the BPL: $\left(\mathrm{H}_{2} \mathrm{O}\right)$ interaction, the relative errors on the dipole moments, rotational constants, binding energy and complexation energy being less than 6\% (Table 1).

It should be underlined that all the levels of theory selected for the present study satisfactorily reproduce the geometric, energetic and spectroscopic features of the 1:1 complex. Accordingly, dispersion-corrected DFT is able to accurately describe the mono-hydrated complex. This feature is in line with other studies on hydrated species [34,45].

\begin{tabular}{|c|c|c|c|c|c|}
\hline & \multicolumn{2}{|c|}{ Distances $(\AA)$} & \multirow{2}{*}{$\begin{array}{c}\text { Energy }(\mathrm{kJ} / \mathrm{mol}) \\
\mathrm{D}_{\mathrm{e}}\left(\mathrm{D}_{\mathrm{e}}^{\mathrm{CP}}\right) / \mathrm{D}_{0}\left(\mathrm{D}_{0} \mathrm{CP}\right)^{\mathrm{a}}\end{array}$} & \multirow{2}{*}{$\frac{\text { Dipole Moment }(\mathrm{D})^{\mathrm{b}}}{\mu_{\mathrm{tot}}\left(\mu_{\mathrm{a}} / \mu_{\mathrm{b}}\right)}$} & \multirow{2}{*}{$\begin{array}{c}\begin{array}{c}\text { Rotational } \\
\text { Constants } \\
(\mathrm{MHz})\end{array} \\
\mathrm{A} / \mathrm{B} / \mathrm{C} \\
\end{array}$} \\
\hline & $\mathrm{r}_{\mathrm{OH} \cdots \mathrm{O}}$ & $\Delta \mathrm{r}_{\mathrm{OH}} / \Delta \mathrm{r}_{\mathrm{CO}}$ & & & \\
\hline Experimental values $^{\mathrm{c}}$ & & & & $2.731(0.996 / 2.53)$ & 6793/2056/1614 \\
\hline CCSD(T)-F12/aVDZ & 98 & 003 & $-29(-2$ & & \\
\hline $\begin{array}{c}\text { CCSD/aVDZ// CCSD(T)- } \\
\text { F12/aVDZ } \\
\end{array}$ & & & & $2.69(0.97 / 2.51)$ & $6772 / 2133 / 1656$ \\
\hline MP2/aVDZ & 1.98 & $0.008 / 0.007$ & $-30(-24) /-23(-16)$ & $2.66(0.94 / 2.49)$ & $6637 / 2111 / 1636$ \\
\hline MP2/aVTZ & 1.96 & $0.009 / 0.007$ & $-29(-26) /-21(-19)$ & $2.65(1.05 / 2.44)$ & $6774 / 2129 / 1654$ \\
\hline B2PLYP/Pop2 & 1.99 & $0.008 / 0.008$ & $-26(-23) /-20(-17)$ & $2.65(1.03 / 2.45)$ & $6877 / 2050 / 1611$ \\
\hline B2PLYP/Pop3 & 1.97 & $0.008 / 0.008$ & $-26(-23) /-19(-16)$ & $2.73(1.20 / 2.45)$ & $6870 / 2058 / 1616$ \\
\hline B2PLYPD/Pop2 & 1.99 & $0.008 / 0.008$ & $-31(-28) /-24(21)$ & $2.65(0.80 / 2.53)$ & $6729 / 2125 / 1649$ \\
\hline B2PLYPD/Pop3 & 1.98 & $0.008 / 0.007$ & $-30(-28) /-23(-20)$ & $2.71(1.00 / 2.52)$ & $6735 / 2127 / 1650$ \\
\hline B2PLYP-GD3BJ/Pop2 & 1.98 & $0.008 / 0.008$ & $-26(-23) /-19(-16)$ & $2.65(0.95 / 2.48)$ & $6824 / 2083 / 1629$ \\
\hline B2PLYP-GD3BJ/Pop3 & 1.97 & $0.008 / 0.008$ & $-25(-23) /-18(-15)$ & $2.72(1.14 / 2.47)$ & $6823 / 2089 / 1632$ \\
\hline$\omega \mathrm{B} 97 \mathrm{XD} / \mathrm{Pop} 1$ & 1.95 & $0.010 / 0.008$ & $-31(-29) /-23(-21)$ & $2.78(1.10 / 2.55)$ & $6861 / 2115 / 1650$ \\
\hline$\omega \mathrm{B} 97 \mathrm{XD} / \mathrm{Pop} 2$ & 1.96 & \begin{tabular}{|l|}
$0.009 / 0.008$ \\
\end{tabular} & $-30(-28) /-22(-21)$ & $2.72(1.09 / 2.49)$ & 6907/2103/1646 \\
\hline$\omega$ B97XD/Pop3 & 2.01 & $0.009 / 0.008$ & $-29(-27) /-21(-19)$ & $2.78(1.30 / 2.45)$ & $6926 / 2095 / 1642$ \\
\hline LC- $\omega$ PBE-GD3BJ/Pop1 & 1.95 & \begin{tabular}{|l|}
$0.009 / 0.007$ \\
\end{tabular} & $-31(-29) /-24(-22)$ & $2.76(1.08 / 2.54)$ & $6905 / 2109 / 1650$ \\
\hline LC- $\omega$ PBE-GD3BJ/Pop2 & 1.97 & $0.008 / 0.008$ & $-29(-28) /-22(-21)$ & $2.71(1.02 / 2.51)$ & $6936 / 2075 / 1627$ \\
\hline LC- $\omega$ PBE-GD3BJ/ Pop3 & 1.96 & $0.009 / 0.007$ & $-28(-27) /-21(-20)$ & $2.76(1.25 / 2.46)$ & $6948 / 2094 / 1643$ \\
\hline B3LYP-GD3BJ/ Pop2 & 1.96 & $0.009 / 0.008$ & $-31(-29) /-23(-22)$ & $2.71(1.10 / 2.49)$ & $6871 / 2075 / 1627$ \\
\hline B3LYP-GD3BJ/ Pop3 & 2.01 & $0.009 / 0.008$ & $-29(-28) /-22(-21)$ & $2.77(1.30 / 2.45)$ & $6893 / 2067 / 1623$ \\
\hline
\end{tabular}

Table 1: Calculated geometries, energetics, dipole moments, and rotational constants associated to the experimental data of the $1: 1$ complex. a) $D_{e}$ is the binding energy, $D_{0}$ the binding energy corrected for the vibrational zero-point-energy. $\mathrm{D}_{\mathrm{e}}{ }^{\mathrm{CP}}$ (respectively $\mathrm{D}_{0}{ }^{\mathrm{CP}}$ ) are the $D_{e}$ (respectively $D_{0}$ ) corrected for BSSE using the CP method. b) $\mu_{C}=0$ experimentally and theoretically at all levels. c) From Ref 35.

The LC- $\omega$ PBE-GD3BJ/Pop2, that simultaneously reproduces the selected geometric, energetic and spectroscopic features with errors less than 5\%, as well as the MP2/aVDZ levels, were selected for the study of larger hydrated complexes. The calculated rotational constants are in good agreement with the experimental data for the BPL: $\left(\mathrm{H}_{2} \mathrm{O}\right)_{2-4}$ (Table 2). Consequently, hereafter the LC- $\omega$ PBE-GD3BJ/Pop2 method will be used to study all the first order properties of BPL: $\left(\mathrm{H}_{2} \mathrm{O}\right)_{\mathrm{n}} \geq 4$.

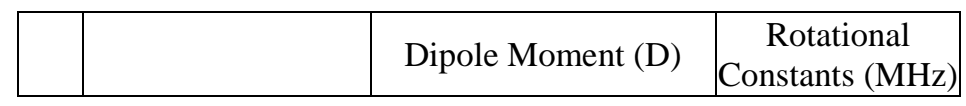




\begin{tabular}{|c|c|c|c|}
\hline & & $\mu_{\mathrm{a}} / \mu_{\mathrm{b}} / \mu_{\mathrm{c}} / \mu_{\text {tot }}$ & $\mathrm{A} / \mathrm{B} / \mathrm{C}$ \\
\hline \multirow{4}{*}{$1: 2$} & Exp & $2.16 / 1.544 / 0.33 / 2.676$ & $2857 / 1730 / 1378$ \\
\cline { 2 - 4 } & MP2/aVDZ & $2.4 / 1.56 / 0.48 / 2.91$ & $2905 / 1775 / 1430$ \\
\cline { 2 - 4 } $1: 3$ & LC- $\omega$ PBE_D3/Pop2 & $2.3 / 1.56 / 0.43 / 2.82$ & $2923 / 1792 / 1425$ \\
\cline { 2 - 4 } $1: 3$ & Exp & $2.357 / 0.6 / 0.12 / 2.435$ & $1861 / 1166 / 884$ \\
\cline { 2 - 4 } & MP2/aVDZ & $2.85 / 0.75 / 0.055 / 2.95$ & $1922 / 1186 / 909$ \\
\hline \multirow{3}{*}{$1: 4 \mathrm{a}$} & LC- $\omega$ PBE_D3/Pop2 & $2.22 / 0.48 / 0.33 / 2.3$ & $1927 / 1169 / 879$ \\
\cline { 2 - 4 } & Exp & $0.503 / 3.785 / 2.667 / 4.657$ & $1234 / 932 / 831$ \\
\hline \multirow{3}{*}{$1: 4 \mathrm{~b}$} & LC- $\omega$ PBE-D3/Pop2 & $0.33 / 3.83 / 2.96 / 4.85$ & $1260 / 956 / 846$ \\
\cline { 2 - 4 } & Exp & $0.44 / 4.16 / 2.98 / 5.14$ & $1272 / 965 / 858$ \\
\cline { 2 - 4 } & MP2/aVDZ & $1.63 / 4.215 / 2.009 / 4.772$ & $1264 / 934 / 828$ \\
\hline
\end{tabular}

Table 2: Experimental and theoretical dipole moments and rotational constants for the BPL: $\left(\mathrm{H}_{2} \mathrm{O}\right)_{2-4}$ clusters.

\section{BPL:( $\left.\mathrm{H}_{2} \mathrm{O}\right)_{4}$ and BPL:( $\left.\mathrm{H}_{2} \mathrm{O}\right)_{5}$ complexes: A MESP picture to rationalize the structures experimentally deduced}

Facial parallel structures were deduced from spectroscopic features for two BPL: $\left(\mathrm{H}_{2} \mathrm{O}\right)_{4}$ and one BPL: $\left(\mathrm{H}_{2} \mathrm{O}\right)_{5}$ isomers, denoted as 1:4a, 1:4b and 1:5a, respectively. In an attempt to shed some light onto the aggregation pattern of water clusters around the solute, we carried out a MESP analysis. A MESP map of free BPL molecule revealed that both trapezoidal faces of the BPL is characterized by:

- two neighboring electron-deficient regions, at two consecutive corners, corresponding to the hydrogen atoms,

- two neighboring electron-rich regions, at two consecutive corners, corresponding to the oxygen atoms,

- an electron-deficient region in the middle of the face (Figure 1).
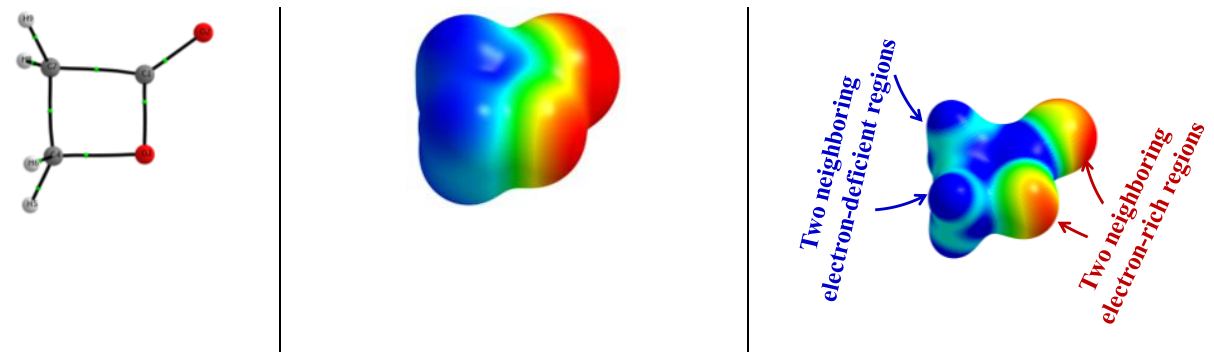

Figure 1: Topological study of the BPL molecule: Structure of the $\beta$-propiolactone (left), MESP map plotted at the 0.001 a.u. (centre) and 0.04 a.u. (right) isodensity surface. Electronrich regions are depicted in red color, while electron-deficient regions are in blue color.

Electron-rich regions of the solute will be attracted towards an electron-deficient region of water clusters, and conversely. This is the starting point in the entrance channel of any noncovalent interaction. As a matter of fact, two species initially adopt the best spatial configuration to maximize the number of complementary MESP regions. The MESP analysis of water clusters (Figure 2) is indeed in line with the structures earlier reported for the BPL: $\left(\mathrm{H}_{2} \mathrm{O}\right)_{4}$ and BPL: $\left(\mathrm{H}_{2} \mathrm{O}\right)_{5}$ isomers: 
$>$ in the case of the BPL: $\left(\mathrm{H}_{2} \mathrm{O}\right)_{4}$ complex, it was found that the water tetramer involved in the interaction with the solute is the uudd isomer, thus called with respect to the orientation of free $\mathrm{OH}$ groups. Both faces of the MESP of this cyclic water tetramer presents two neighboring electron-deficient regions (corresponding to the hydrogen atoms) followed by two neighboring electron-rich regions (corresponding to the oxygen atoms). As shown in Figure 2, such a MESP can perfectly complement the one of the solute,

$>$ in the case of the BPL: $\left(\mathrm{H}_{2} \mathrm{O}\right)_{5}$ complex, the cyclic $u d u d u$ water pentamer was found to be distorted by the interaction with the solute. This distortion is in line with the MESP picture of both partners: four of the five water molecules have suitable, complementary MESP features for interaction with the solute, and the fifth one is puckered away from the solute.

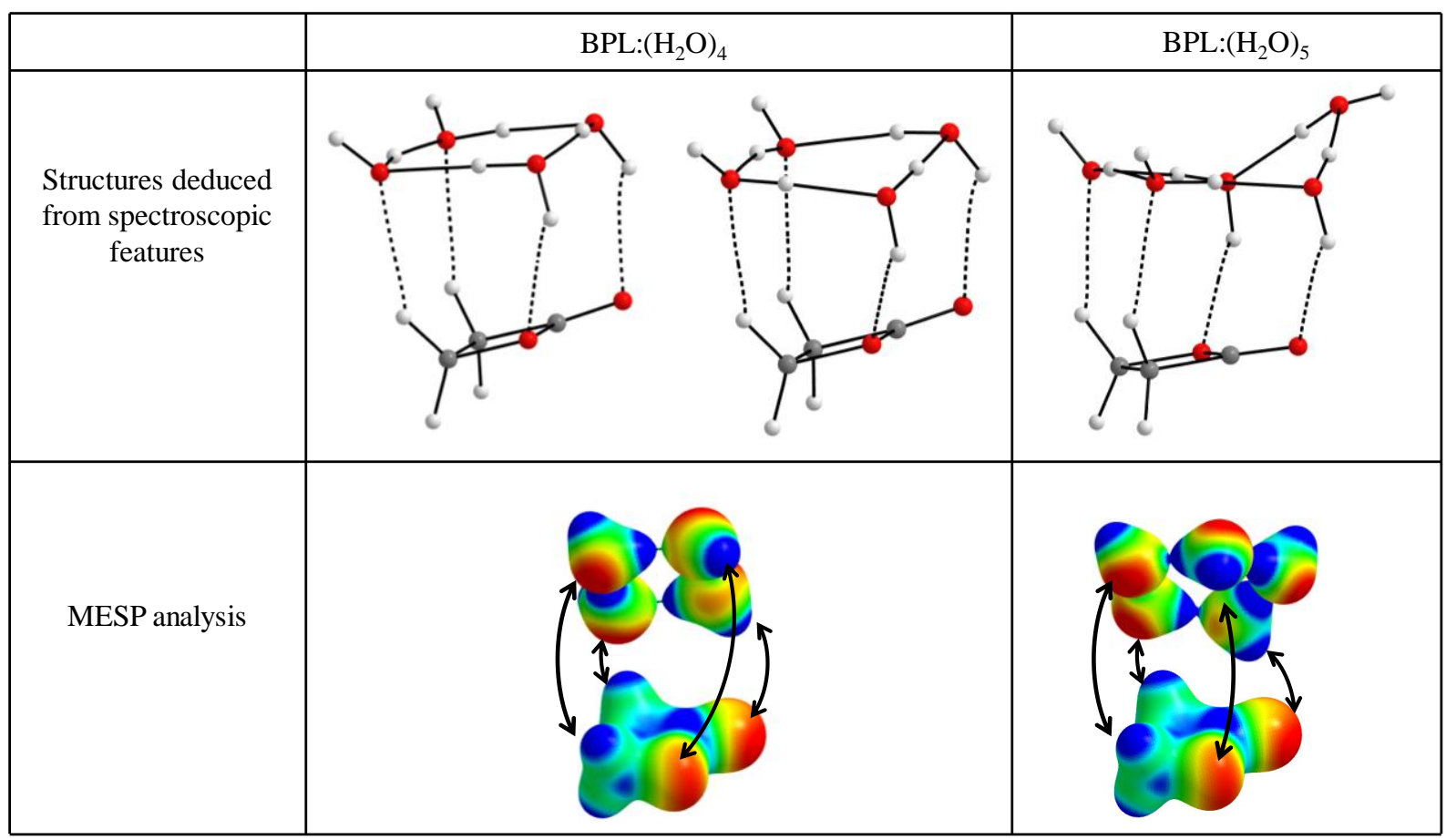

Figure 2: Experimentally-deduced structures for the BPL: $\left(\mathrm{H}_{2} \mathrm{O}\right)_{4}$ and BPL: $\left(\mathrm{H}_{2} \mathrm{O}\right)_{5}$ clusters and identification of the complementary interacting sites by the MESP analysis of isolated partners.

As underlined by Alonso et al. [35] an inversion in the hydrogen bonding network in the water cluster leads to two similar isomers for the BPL: $\left(\mathrm{H}_{2} \mathrm{O}\right)_{4}$ complex. Similarly, our calculations also lead to the prediction of two almost isoenergetic isomers for the BPL: $\left(\mathrm{H}_{2} \mathrm{O}\right)_{5}$ complex, differing from one another by an inversion in the hydrogen bonding network in the water cluster.

It was found that both isomers of the BPL: $\left(\mathrm{H}_{2} \mathrm{O}\right)_{4}$ and of BPL: $\left(\mathrm{H}_{2} \mathrm{O}\right)_{5}$ complexes correspond to stable structures at the chosen level of theory. To further characterize the water-solute interaction in the equilibrium structures, the BCPs obtained from the QTAIM analysis were used to identify the interacting atoms, and to quantitatively describe the water-solute interaction by measure of the electron density $\rho(\mathbf{r})$ and Laplacian $\nabla^{2} \rho(\mathbf{r})$ at BPCs between 
water molecules and the solute. The interaction between water cluster and the solute for that both isomers of the BPL: $\left(\mathrm{H}_{2} \mathrm{O}\right)_{4}$ and of BPL: $\left(\mathrm{H}_{2} \mathrm{O}\right)_{5}$ complexes is characterized by four BCPs denoted as $\mathrm{H}_{\mathrm{w}}-\mathrm{O}_{\mathrm{k}}, \mathrm{H}_{\mathrm{w}}-\mathrm{O}_{\mathrm{e}}, \mathrm{O}_{\mathrm{w}}-\mathrm{H}_{\mathrm{m}}$, and $\mathrm{O}_{\mathrm{w}}-\mathrm{H}_{\mathrm{m}}$ with respect to the atoms involved in these interactions. Their energetic and topological features are reported in Table 3.

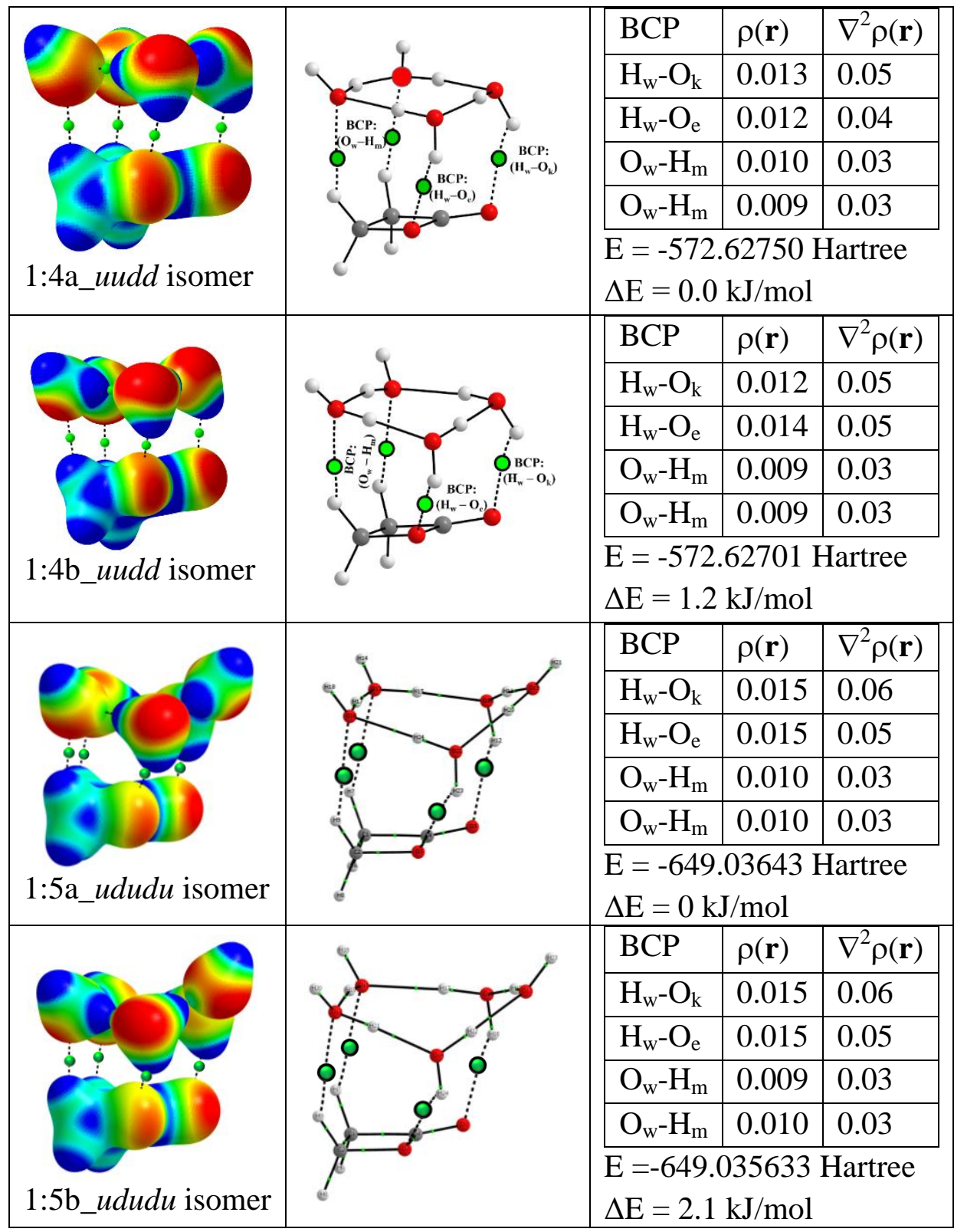

Table 3: MESP plot and BCPs of 1:4_uudd and 1:4_ududu isomers. See the caption of Figure 1 for more information.

The calculated dipole moments and rotational constants for these BPL: $\left(\mathrm{H}_{2} \mathrm{O}\right)_{4}$ and BPL: $\left(\mathrm{H}_{2} \mathrm{O}\right)_{5}$ isomers are reported in Table 4.

\begin{tabular}{|c|c|c|c|}
\hline & & $\begin{array}{c}\text { Dipole Moment (D) } \\
\mu_{\mathrm{a}} / \mu_{\mathrm{b}} / \mu_{\mathrm{c}} / \mu_{\mathrm{tot}}\end{array}$ & $\begin{array}{c}\text { Rotational } \\
\text { Constants }(\mathrm{MHz}) \\
\mathrm{A} / \mathrm{B} / \mathrm{C}\end{array}$ \\
\hline \multirow{3}{*}{$\mathrm{BPL}:\left(\mathrm{H}_{2} \mathrm{O}\right)_{4}$} & Experimental data [35] & $0.503 / 3.785 / 2.667 / 4.657$ & $1234 / 932 / 831$ \\
\cline { 2 - 4 } & Experimental data [35] & $0.985 / 4.215 / 2.009 / 4.772$ & $1264 / 934 / 828$ \\
\hline
\end{tabular}




\begin{tabular}{|c|c|c|c|}
\hline & 1:4a_uudd isomer & $0.44 / 4.16 / 2.98 / 5.14$ & $1272 / 965 / 858$ \\
\hline & 1:4b_uudd isomer & $0.89 / 4.59 / 2.44 / 5.27$ & $1295 / 962 / 856$ \\
\hline \multirow{3}{*}{ BPL: $\left(\mathrm{H}_{2} \mathrm{O}\right)_{5}$} & Experimental data [35] & & $946 / 654 / 642$ \\
\hline & 1:5a ududu isomer & $2.36 / 1.78 / 3.58 / 4.64$ & $960 / 682 / 664$ \\
\hline & $1: 5 \mathrm{~b} \_u d u d u$ isomer & $2.92 / 2.25 / 4.44 / 5.78$ & $952 / 698 / 640$ \\
\hline
\end{tabular}

Table 4: Experimental and calculated dipole moments and rotational constants for the BPL: $\left(\mathrm{H}_{2} \mathrm{O}\right)_{4}$ and BPL: $\left(\mathrm{H}_{2} \mathrm{O}\right)_{5}$ complexes.

It is remarkable that the experimentally identified BPL: $\left(\mathrm{H}_{2} \mathrm{O}\right)_{4}$ and BPL: $\left(\mathrm{H}_{2} \mathrm{O}\right)_{5}$ isomers involve similar water-solute interactions, as demonstrated by the QTAIM analysis. The above-described structures suggest that the following features of the solvent cluster may favor an efficient facial-parallel interaction with BPL: four almost coplanar water molecules with two consecutive electron-rich regions (oxygen atoms) that may interact with the electrondeficient region of the BPL (hydrogen atoms of the $-\mathrm{CH}_{2}$ - groups), and two consecutive electron- deficient regions (hydrogen atoms) that may interact with the electron-rich region of the BPL (ester function). We thus selected appropriate isomers of $\left(\mathrm{H}_{2} \mathrm{O}\right)_{6}$ and $\left(\mathrm{H}_{2} \mathrm{O}\right)_{10}$ clusters sharing such features, and determined whether they may attach the solute in a similar facial-parallel manner as the water tetramer and pentamer do.

\section{BPL: $\left(\mathrm{H}_{2} \mathrm{O}\right)_{6}$ complex}

Different $\left(\mathrm{H}_{2} \mathrm{O}\right)_{6}$ isomers were identified for the water hexamer: the tridimensional prism, cage and book are almost isoenergetic, whereas the cyclic isomer is slightly higher in energy $[46,47]$.The MESPs of each of these isomers are presented in Figure 3.

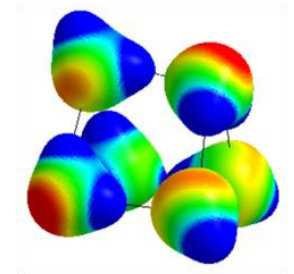

Prism $0.0 \mathrm{~kJ} / \mathrm{mol}$

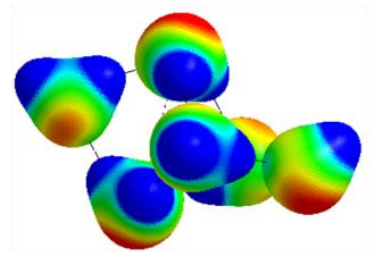

Cage $1.6 \mathrm{~kJ} / \mathrm{mol}$

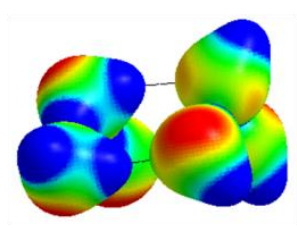

Book

$2.1 \mathrm{~kJ} / \mathrm{mol}$

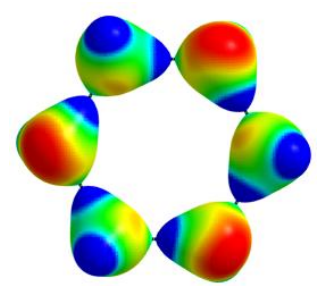

Cyclic

$7.1 \mathrm{~kJ} / \mathrm{mol}$

Figure 3: MESP plot of the water hexamer isomers.

One face of the prism isomer presents a similar MESP to the one of the uudd water tetramer, with two consecutive electron-rich regions followed by two consecutive electron-deficient regions. The book isomer also contains four almost coplanar water molecules presenting a complementary MESP feature with respect to the one of the BPL. (Figure 4) The two other isomers do not present two consecutive electron-rich regions followed by two consecutive electron-deficient regions. Thus, the possible interaction of BPL with the cage and cyclic isomers was not further investigated. 



Figure 4: The presence of two neighboring electron-deficient regions followed by two neighboring electron-rich regions on the rectangular base of the prism (A) and book (B) structures promote the electrostatic interaction with BPL in a facial parallel arrangement.

Geometry optimizations confirm that both prism and book isomers can efficiently attach the solute in a facial parallel arrangement. A QTAIM analysis carried out on relaxed structures lied to the identification of four BCPs between the water cluster and the solute: $\mathrm{H}_{\mathrm{w}}-\mathrm{O}_{\mathrm{k}}, \mathrm{H}_{\mathrm{w}}-\mathrm{O}_{\mathrm{e}}$, $\mathrm{O}_{\mathrm{w}}-\mathrm{H}_{\mathrm{m}}$, and $\mathrm{O}_{\mathrm{w}}-\mathrm{H}_{\mathrm{m}}$ (Table 5). Thus, two isomers of the $\left(\mathrm{H}_{2} \mathrm{O}\right)_{6}$ cluster could attach the BPL through similar interactions to those involved in the experimentally identified BPL: $\left(\mathrm{H}_{2} \mathrm{O}\right)_{4}$ and BPL: $\left(\mathrm{H}_{2} \mathrm{O}\right)_{5}$ isomers.

\begin{tabular}{|l|l|l|l|}
\hline \begin{tabular}{l}
$\mathrm{BCP}$ \\
\hline
\end{tabular} & $\rho(\mathbf{r})$ & $\nabla^{2} \rho(\mathbf{r})$ \\
\hline $\mathrm{H}_{\mathrm{w}}-\mathrm{O}_{\mathrm{k}}$ & 0.019 & 0.08 \\
\hline $\mathrm{H}_{\mathrm{w}}-\mathrm{O}_{\mathrm{e}}$ & 0.014 & 0.05 \\
\hline $\mathrm{O}_{\mathrm{w}}-\mathrm{H}_{\mathrm{m}}$ & 0.013 & 0.04 \\
\hline $\mathrm{O}_{\mathrm{w}}-\mathrm{H}_{\mathrm{m}}$ & 0.010 & 0.03 \\
\hline $\mathrm{E}=-725.44600$ Hartree \\
$\Delta \mathrm{E}=0 \mathrm{~kJ} / \mathrm{mol}$
\end{tabular}

Table 5: MESP plot and BCPs of BPL: $\left(\mathrm{H}_{2} \mathrm{O}\right)_{6}$. 


\section{BPL: $\left(\mathrm{H}_{2} \mathrm{O}\right)_{10}$ complex}

The most stable isomer for the water decamer is constituted of two stacked dudud pentameric plans [47].The MESP of one of the rectangular face presents two consecutive electron-rich regions followed by two consecutive electron-deficient regions (Table 6), that may efficiently attach the solute.

From the above discussed MESP analysis of the water clusters that may lead to a favorable facial interaction with the solute, it can be anticipated that an alternative water decamer could also favorably attach the BPL. Indeed, the flip of some hydrogen atoms leads to a new isomer constituted of two pentagonal duuud faces. The MESP of the pentagonal face of such an isomer is characterized by two consecutive electron-rich regions followed by three consecutive electron-deficient regions. Thus, the pentagonal face of this isomer is suitable for interaction with the BPL (Table 6). Geometry optimization indeed confirms that a water decamer cluster may attach the solute either by a rectangular face of the $d u d u d$ isomer or by a pentagonal face of the duuud isomer. In both cases, a facial parallel structure characterized by four BCPs between the water cluster and the solute $\left(\mathrm{H}_{\mathrm{w}}-\mathrm{O}_{\mathrm{k}}, \mathrm{H}_{\mathrm{w}}-\mathrm{O}_{\mathrm{e}}, \mathrm{O}_{\mathrm{w}}-\mathrm{H}_{\mathrm{m}}\right.$, and $\left.\mathrm{O}_{\mathrm{w}}-\mathrm{H}_{\mathrm{m}}\right)$ is obtained (Table 6).

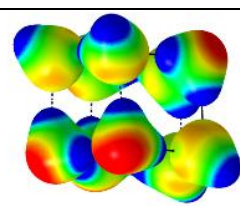

dudud isomer: $\mathrm{Te}=0.0 \mathrm{~kJ} / \mathrm{mol}[47]$



duuиd isomer: Te $=17.7 \mathrm{~kJ} / \mathrm{mol}[47]$



Table 6: Study of the BPL: $\left(\mathrm{H}_{2} \mathrm{O}\right)_{10}$ isomer. 
Thus, facial parallel structures characterized by four BCPs between the solute and a water cluster, and similar to the ones observed for the BPL: $\left(\mathrm{H}_{2} \mathrm{O}\right)_{4,5}$ complexes, may exist for the larger BPL: $\left(\mathrm{H}_{2} \mathrm{O}\right)_{6,10}$ complexes.

In the case of the BPL: $\left(\mathrm{H}_{2} \mathrm{O}\right)_{10}$ complex, we alternatively considered two isomers in which two water clusters are simultaneously interacting with the BPL (Fig. 5):

- a $\left(\mathrm{H}_{2} \mathrm{O}\right)_{5}: \mathrm{BPL}:\left(\mathrm{H}_{2} \mathrm{O}\right)_{5}$ isomer in which each water pentamer is interacting with one face of the solute,

- a $\left(\mathrm{H}_{2} \mathrm{O}\right)_{4}: \mathrm{BPL}:\left(\mathrm{H}_{2} \mathrm{O}\right)_{6}$ isomer in which a $u$ udd water tetramer is attached to one face of the BPL whereas a water hexamer in its book shape is interacting with the other face.

The QTAIM analysis on the relaxed 5:1:5 and 6:1:4 structures demonstrates that each water cluster is attached to the solute by means of four interactions: $\mathrm{H}_{\mathrm{w}}-\mathrm{O}_{\mathrm{k}}, \mathrm{H}_{\mathrm{w}}-\mathrm{O}_{\mathrm{e}}, \mathrm{O}_{\mathrm{w}}-\mathrm{H}_{\mathrm{m}}$, and $\mathrm{O}_{\mathrm{w}^{-}}$ $\mathrm{H}_{\mathrm{m}}$. However, both 5:1:5 and 6:1:4 isomers are significantly higher in energy than the 1:10 isomer by $\sim 40 \mathrm{~kJ} / \mathrm{mol}$, thus suggesting that BPL: $\left(\mathrm{H}_{2} \mathrm{O}\right)_{n}$ isomers in which a single water cluster is interacting with the solute would be preferentially formed rather than sandwich $\left(\mathrm{H}_{2} \mathrm{O}\right)_{\mathrm{m}}: \mathrm{BPL}:\left(\mathrm{H}_{2} \mathrm{O}\right)_{\mathrm{n}-\mathrm{m}}$ arrangements.

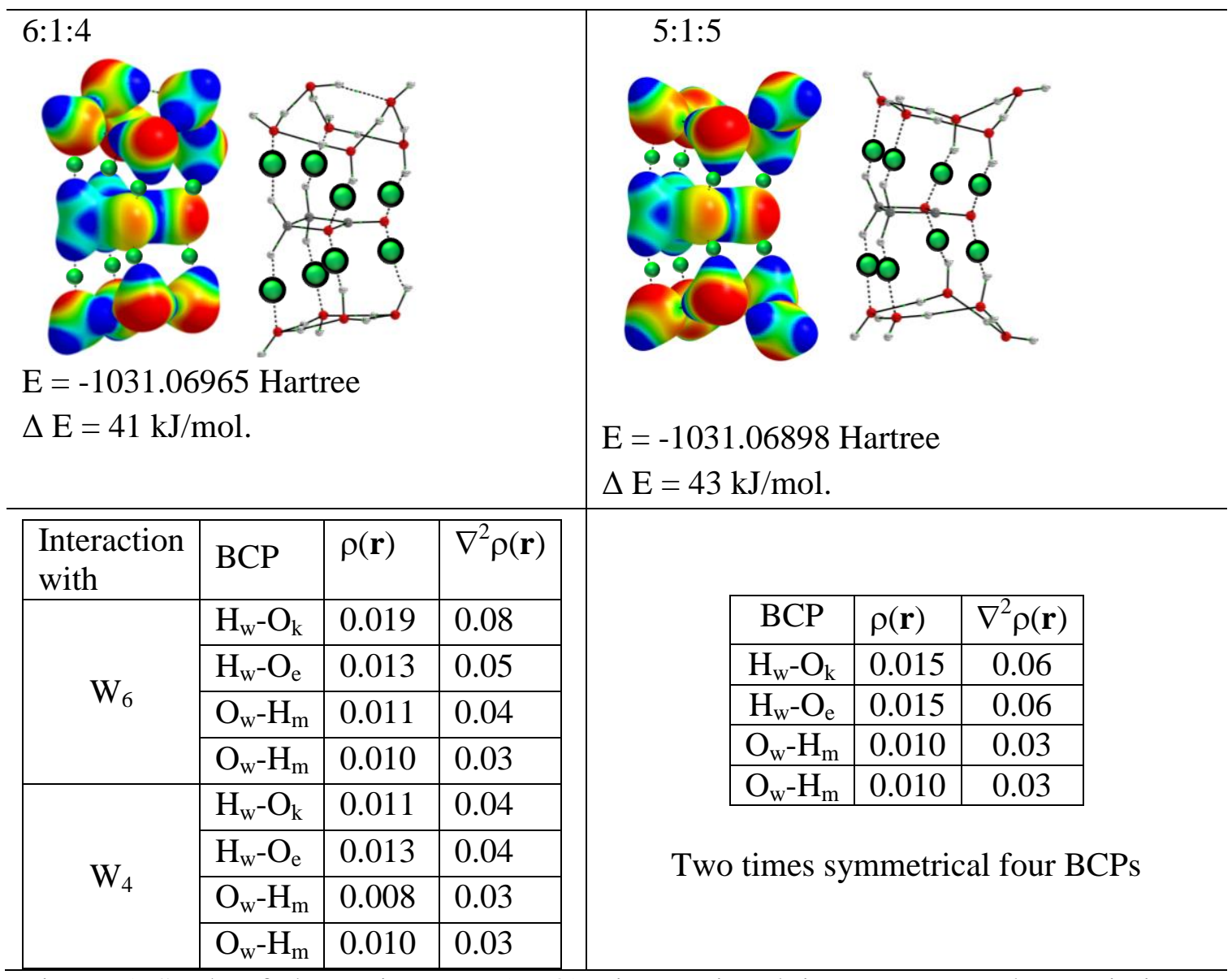

Figure 5: Study of alternative BPL: $\left(\mathrm{H}_{2} \mathrm{O}\right)_{10}$ isomer involving two water clusters in interaction with the solute. 


\section{BPL in or out of water cluster: BPL: $\left(\mathrm{H}_{2} \mathrm{O}\right)_{20}$ and BPL:( $\left.\mathrm{H}_{2} \mathrm{O}\right)_{24}$ complexes}

The study of larger BPL: $\left(\mathrm{H}_{2} \mathrm{O}\right)_{n}$ clusters is particularly relevant in the context of clathrate hydrate formation. Endohedral and exohedral BPL: $\left(\mathrm{H}_{2} \mathrm{O}\right)_{20,24}$ involving the $5^{12}$ and $5^{12} 6^{2}$ standard water cages, respectively, were considered (Table 7).

First of all, we remind the reader that the global minimum reported in the literature for both $\left(\mathrm{H}_{2} \mathrm{O}\right)_{20}$ and $\left(\mathrm{H}_{2} \mathrm{O}\right)_{24}$ cluster are cuboidal $[19,48-53]$ in which the insertion sites are too small to accept a guest polyatomic molecule without opening the water network. The $\left(\mathrm{H}_{2} \mathrm{O}\right)_{20}$ cuboidal structure was confirmed at the MP2 perturbative level of theory [49], while the $\left(\mathrm{H}_{2} \mathrm{O}\right)_{24}$ cuboidal structure has been identified based on molecular dynamic calculations [Erreur ! Signet non défini.]. However, it is also well known that the unit cell of a host-guest interaction in gas hydrates consists of two hollow $5^{12}\left(\mathrm{H}_{2} \mathrm{O}\right)_{20}$ (dodecahedron) and six hollow $5^{12} 6^{2}\left(\mathrm{H}_{2} \mathrm{O}\right)_{24}$ (tetrakaidecahedron) cages. The simplest $\left(\mathrm{H}_{2} \mathrm{O}\right)_{20}$ dodecahedron structure used in this work corresponds to the lowest lying isomers D-cage containing twelve pentagonal rings which is energetically less stable than the Edge sharing structure (singlet ground electronic state) by $\sim 46 \mathrm{kJmol}^{-1}$ [48]. Concerning the hollow $\left(\mathrm{H}_{2} \mathrm{O}\right)_{24}$ tetrakaidecahedron structure, Xantheas et al. identified theoretically three family isomers depending on the acceptor/donor characteristic of the bonded $\mathrm{O}-\mathrm{H}$ bonds and also upon the orientation of dangling O-H bonds (noted as I, II and III) located within a narrow energy windows less than $2.5 \mathrm{kJmol}^{-1}[54,55,56,57]$. The hollow $5^{12} 6^{2}\left(\mathrm{H}_{2} \mathrm{O}\right)_{24} \mathrm{~T}$-cage considered in this work corresponds to the lowest-lying "family I isomers" of Xantheas. At the present level of theory, the $\left(\mathrm{H}_{2} \mathrm{O}\right)_{24}$ T-cage was found to be $93.8 \mathrm{kJmol}^{-1}$ above the the global minimum of cuboid $\left(\mathrm{H}_{2} \mathrm{O}\right)_{24}$ suggested by Takeuchi [53].Furthermore, this T-cage structure has been used to study the stability and reactivity of $\mathrm{CH}_{4}$ encapsulated in the $5^{12} 6^{2}$ cage [57]. Concerning the interaction of a BPL molecule with either $5^{12}\left(\mathrm{H}_{2} \mathrm{O}\right)_{20}$ D-cage or $5^{12} 6^{2}\left(\mathrm{H}_{2} \mathrm{O}\right)_{24}$ T-cage, the exohedral structure obeys the same rules as for above studied complexes: the $5^{12}$ or $5^{12} 6^{2}$ cage interacts with BPL by a pentagonal face offering the most favorable MESP feature, and four S-W BCPs are identified.

The inclusion of BPL inside the $5^{12}$ cage - BPL@ $\left(\mathrm{H}_{2} \mathrm{O}\right)_{20}$ - generates 19 BCPs including two characteristics of the hydrogen bonding between the hydrogen of waters and the ketone oxygen of BPL, which leads to the formation of a solute-induced Bjerrum-like defect, as observed in the encapsulation of several solutes [18]. Nevertheless, the endohedral isomer is found to be slightly less stable than the exohedral form, by $\sim 8.3 \mathrm{kJmol}^{-1}$.

Contrarily, the endohedral isomer is more stable than the exohedral one by $\sim 21.7 \mathrm{kJmol}^{-1}$, for the BPL: $\left(\mathrm{H}_{2} \mathrm{O}\right)_{24}$ complex. A larger cavity of the $5^{12} 6^{2}$ structure $(\bar{r}=4.33 \AA$ vs. $3.95 \AA$ for the $5^{12}$ dodecahedron cluster) [58] allows the BPL encapsulation without any defect on the water network. The guest molecule is found in sandwich between two hexagonal rings of the $5^{12} 6^{2}$ structure. According to the QTAIM analysis (Table 8), multiple oxygen-oxygen interactions are formed between the solute and the cage, in addition to the hydrogen bonding involving hydrogen atoms of BPL. 




Table 7: MESP of the $5^{12}$ and $5^{12} 6^{2}$ water cages are plotted at $\rho(\mathbf{r})=0.001$ a.u. Optimized geometries for both endo- and exohedral BPL: $\left(\mathrm{H}_{2} \mathrm{O}\right)_{20,24}$ complexes.

\begin{tabular}{|c|c|c|}
\hline $\mathrm{BCP}$ & $\rho(\mathbf{r}) / \nabla^{2} \rho(\mathbf{r})$ & Remarks \\
\hline $\mathrm{O}_{\text {ket }}-\mathrm{O}_{\text {water }}$ & $\begin{array}{l}0.005 /+0.02 \\
0.006 /+0.02 \\
0.008 /+0.03 \\
0.008 /+0.03 \\
0.008 /+0.03 \\
0.011 /+0.05 \\
\end{array}$ & $\begin{array}{l}\text { The ketone oxygen } \\
\text { atom of BPL }\end{array}$ \\
\hline $\mathrm{O}_{\text {eth }}-\mathrm{O}_{\text {water }}$ & $\begin{array}{l}0.003 /+0.01 \\
0.004 /+0.02 \\
0.005 /+0.02 \\
0.006 /+0.02 \\
\end{array}$ & $\begin{array}{l}\text { The ether oxygen } \\
\text { atom of BPL }\end{array}$ \\
\hline$\left(\mathrm{O}_{\text {eth }}\right) \mathrm{C}-\mathrm{O}_{\text {water }}$ & $0.003 /+0.01$ & $\begin{array}{l}\text { The Carbon atom } \\
\text { close to } \mathrm{O}_{\text {ether }}\end{array}$ \\
\hline$(\mathrm{HC}) \mathrm{H}-\mathrm{O}_{\text {water }}$ & $\begin{array}{l}0.003 /+0.01 \\
0.005 /+0.02 \\
0.008 /+0.03 \\
\end{array}$ & $\begin{array}{l}\text { The hydrogen atom } \\
\text { of } \mathrm{CH}_{2} \\
\text { group close to } \mathrm{O}_{\text {ether }}\end{array}$ \\
\hline$(\mathrm{HC}) \mathrm{H}-\mathrm{O}_{\text {water }}$ & $\begin{array}{l}0.005 /+0.02 \\
0.006 /+0.02 \\
0.008 /+0.03 \\
\end{array}$ & $\begin{array}{l}\text { The hydrogen atom } \\
\text { of } \mathrm{CH}_{2} \\
\text { group close to } \mathrm{O}_{\text {ether }}\end{array}$ \\
\hline$(\mathrm{HC}) \mathrm{H}-\mathrm{O}_{\text {water }}$ & $\begin{array}{l}0.005 /+0.02 \\
0.006 /+0.02 \\
0.006 /+0.02 \\
\end{array}$ & \\
\hline$(\mathrm{HC}) \mathrm{H}-\mathrm{O}_{\text {water }}$ & $0.003 /+0.01$ & \\
\hline
\end{tabular}


Table 8: Electron density (in a.u.) and its Laplacian (in a.u.) at the BCPs between different atoms of BPL and oxygen atoms of the $5^{12} 6^{2}$ cage.

A total of ten BCPs have been found between two oxygen atoms of BPL and those of water molecules. For these $\mathrm{O}_{\mathrm{k}}-\mathrm{O}_{\mathrm{w}}$ and $\mathrm{O}_{\mathrm{e}}-\mathrm{O}_{\mathrm{w}}$ BCPs, the electron density varies between 0.003 and 0.011 a.u. These values are very close to the ones of the oxygen-oxygen interactions involved in the $\mathrm{CO}_{2} @\left(\mathrm{H}_{2} \mathrm{O}\right)_{20}$ endohedral complex ( $\rho=$ [0.004 - 0.008 a.u.] [16]). We should underline that the $\mathrm{H}_{\mathrm{m}}-\mathrm{O}_{\mathrm{w}}$ interactions are far from being negligible with respect to the $\mathrm{O}_{\mathrm{k}}-\mathrm{O}_{\mathrm{w}}$ and $\mathrm{O}_{\mathrm{e}}-\mathrm{O}_{\mathrm{w}}$ ones. Consequently, both van-der-Waals $\mathrm{O}_{\mathrm{BPL}}-\mathrm{O}_{\mathrm{w}}$ interaction and hydrogen $\mathrm{H}_{\mathrm{m}}-\mathrm{O}_{\mathrm{w}}$ bonding contribute to the stability of the BPL@ $\left(\mathrm{H}_{2} \mathrm{O}\right)_{24}$ endohedral complex.

\section{Conclusion}

In summary, the dispersion corrected range-separated-hybrid functional LC-wPBE-GD3BJ combined with a moderate size basis set $(6-311++\mathrm{G}(\mathrm{d}, \mathrm{p}))$ was found to suitably describe the geometric, energetic and spectroscopic (dipole moments and rotational constants) features of micro-hydrated BPL: $\left(\mathrm{H}_{2} \mathrm{O}\right)_{n}$ complexes. Facial parallel structures previously reported for the BPL: $\left(\mathrm{H}_{2} \mathrm{O}\right)_{4,5}$ complexes were rationalized thanks to the MESP analysis of isolated partners. The QTAIM analysis further demonstrates that attachment of the water cluster on the BPL is similar in these BPL: $\left(\mathrm{H}_{2} \mathrm{O}\right)_{4,5}$ complexes. It was further shown that two isomers of water hexamer and water decamer could efficiently attach the solute by means of similar watersolute interactions characterized by four BPCs between water molecules and the solute.

Larger water clusters may also similarly interact with the solute: the attachment of the $5^{12}$ and $5^{12} 6^{2}$ water D- and T-cages on the solute leads to a substantial stabilization of the system. Alternatively these water cages can also act as host for the solute. DFT-D calculations confirm that both endohedral and exohedral BPL: $\left(\mathrm{H}_{2} \mathrm{O}\right)_{20,24}$ complexes are stable with respect to the lowest lying D- and T-cage added to free BPL molecule. Nevertheless, it is interesting to note that these endohedral compounds lie around ten $\mathrm{kJmol}^{-1}$ above the sum of free partners when we take into account the global minimum of water cluster of cuboid structure. In the BPL@ $\left(\mathrm{H}_{2} \mathrm{O}\right)_{20}$ isomer, the BPL simultaneously acts as hydrogen-bond donor and hydrogenbond acceptor to the water cluster, and the formation of solute-induced Bjerrum-like defects results in an opening of the water cage. As a result, the endohedral and exohedral BPL: $\left(\mathrm{H}_{2} \mathrm{O}\right)_{20}$ isomers are calculated to be close in energy. Such disruption of the water-water interaction is not observed when BPL is inserted inside the larger $5^{12} 6^{2}$ water cage. The BPL@ $\left(\mathrm{H}_{2} \mathrm{O}\right)_{24}$ isomer is much more stable than the exohedral BPL: $\left(\mathrm{H}_{2} \mathrm{O}\right)_{24}$ isomer. This can easily be explained from the QTAIM analysis that leads to the identification of 22 BCPs between oxygen atoms of water molecules and the solute in the inclusion complex, whereas only four BCPs are involved in the exohedral interaction.

\section{Supporting Information}


Cartesian coordinates of all the studied species are reported in the Supporting Information. This includes the Cartesian coordinates of the cuboidal $\left(\mathrm{H}_{2} \mathrm{O}\right)_{20}$ and $\left(\mathrm{H}_{2} \mathrm{O}\right)_{24}$ isomers. Spectrospic features are also gathered for the BPL: $\left(\mathrm{H}_{2} \mathrm{O}\right)_{\mathrm{n}}$ complexes.

Note: The authors declare no competing financial interest.

\section{Acknowledgement}

We thank the UPMC labex MiChem for providing Ph.D. financial support for M. Kalai. We are grateful to IDRIS for providing computer facilities (Grant No. i2016087615).

1 Rodgers MT, Armentrout PB (2016) Chem Rev 116:5642-5687

2 Hobza P, Muller-Dethlefs K (2010) Non-covalent interactions: Theory and experiment. Royal Society of Chemistry

3 Subha Mahadevi A, Narahari Sastry G (2016) Chem Rev 116:2775-2825

4 Wei Z, Chen D, Zhao H, Li Y, Zhu J, Liu B (2014) J Chem Phys 140:085103_1-085103_10

5 Bouchet A, Schìtz M, Dopfer O (2016) Chem Phys Chem 17:232-243

6 Feng G, Gou Q, Evangelisti L, Spada L, Blanco S, Caminati W (2016) Phys Chem Chem Phys 18:23651-23656

7 Fogarasi G, Szalay PG (2015) Phys Chem Chem Phys 17:29880-29890

8 Chen D, Wei Z, Liu B (2015) J Mol Model 21:234-242

9 Riffet V, Bouchoux G, Frison G (2015) J Phys Chem B 119:11527-11539

10 Pérez C, Zaleski DP, Seifert NA, Temelso B, Shields GC, Kisiel Z, Pate BH (2014) Angew Chem Int Ed 53:14368-14372

11 Dargent D, Zins EL, Madebène B, Alikhani ME (2016) Theor Chem Acc 135:32_1-32_12 12 Zelenẏ T, Hobza P, Kabeláč M (2009) Phys Chem Chem Phys 11:3430-3435

13 Calvo F, Bacchus-Montabonel MC, Clavaguéra C (2016) J Phys Chem A 120:2380-2389

14 Miliordos E, Aprà E, Xantheas SS (2016) J Chem Theory and Compu. 12:4004-4014

15 Park SS, Lee S, Won YS, Ahn YJ (2014) Chem Phys 441:128-136

16 Kumar P, Sathyamurthy N (2011) J Phys Chem A 115:14276-14281

17 Bader RFW (1990) Atoms in Molecules. A Quantum Theory. Clarendon, Oxford, UK

18 Alavi S, Susilo R, Ripmeester JA (2009) J Chem Phys 130:174501_1-174501_8

19 Gadre SR, Yeole SD, Sahu N (2014) Chem Rev 114:12132-12173

20 Murray JS, Sen K (1996) Molecular Electrostatic Potentials: Concepts and Applications, Elsevier Science, Amsterdam, The Netherlands

21 Kolár MH, Hobza P (2016) Chem Rev 116:5155-5187

22 Murray JS, Lane P, Clark T, Riley KE, Politzer P (2012) J Mol Model 18:541-548

23 Bauz A, Mooibroek TJ, Frontera A (2015) Chem Phys Chem 16:2496-2517

24 Remya K, Suresh CH (2015) Phys Chem Chem Phys 17:27035-27044

25 Kumar A, Gadre SR, Mohan N, Suresh CH (2014) J Phys Chem A 118:526-532

26 Singh G, Verma R, Gadre SR (2015) J Phys Chem A 119:13055-13063

27 Prakash M, Subramanian V, Gadre SR (2009) J Phys Chem A 113:12260-12275

28 Misquitta AJ, Stone AJ, Price SL (2008) J Chem Theor Comput, 4:19-32. 
29 Stone A (2013) The theory of intermolecular forces. OUP Oxford

30 Gadre SR, Pundlik SS (1997) J Phys Chem B, 101:3298-3303

31 Gadre SR, Kumar A (2015) In: Scheiner S (ed) Noncovalent forces. Springer International Publishing

32 Pathak RK, Gadre SR (1990) J Chem Phys, 93:1770-1773

33 Zins EL, Alikhani ME (2016) Mol Phys, 114:1317-1325

34 Copeland KL, Tschumper GS (2012). J Chem Theor Comput, 8:1646-1656

35 Pérez C, Neill JL, Muckle MT, Zaleski DP, Peña I, Lopez JC, Alonso JL, Pate BH (2015)

Angew Chem Int Ed 54:979-982

36 Koch U, Popelier PLA (1995) J Phys Chem 99:9747-9754

Popelier PLA (1998) J Phys Chem 102:1873-1878

37 Gaussian 09, Revision E.01, Frisch MJ, Trucks GW, Schlegel HB, Scuseria GE, Robb MA, Cheeseman JR, Scalmani G, Barone V, Mennucci B, Petersson GA, Nakatsuji H, Caricato M, Li X, Hratchian HP, Izmaylov AF, Bloino J, Zheng G, Sonnenberg JL, Hada M, Ehara M, Toyota K, Fukuda R, Hasegawa J, Ishida M, Nakajima T, Honda Y, Kitao O, Nakai H, Vreven T, Montgomery JA, Peralta JE, Ogliaro F, Bearpark M, Heyd JJ, Brothers E, Kudin KN, Staroverov VN, Kobayashi R, Normand J, Raghavachari K, Rendell A, Burant JC, Iyengar SS, Tomasi J, Cossi M, Rega N, Millam JM, Klene M, Knox JE, Cross JB, Bakken V, Adamo C, Jaramillo J, Gomperts R, Stratmann RE, Yazyev O,Austin AJ, Cammi R, Pomelli C, Ochterski JW, Martin RL, Morokuma K, Zakrzewski VG, Voth GA, Salvador P, Dannenberg JJ, Dapprich S, Daniels AD, Farkas Ö, Foresman JB, Ortiz JV, Cioslowski J, Fox DJ (2009) Gaussian, Inc., Wallingford CT

38 Grimme S, Antony J, Ehrlich S, Krieg H (2010) J Chem Phys 132:154104_1-15104_19

39 Lee C, Yang WT, Parr RG (1988) Phys Rev B 37:785-789

40 Grimme S (2006) J Chem Phys 124:034108_1-034108_16

41 Vydrov OA, Scuseria GE (2006) J Chem Phys 125:234109_1-234109_9

42 Vydrov OA, Heyd J, Krukau A, Scuseria GE (2006) J Chem Phys 125:074106_1074106_9

43 Vydrov OA, Scuseria GE, Perdew JP (2007) J Chem Phys 126, 154109_1-154109_9

44 Keith TA, AIMAll (Version 14.10.27), TK Gristmill Software, Overland Park KS, USA, 2014 (aim.tkgristmill.com)

45 Liu Y, Zhao J, Li F, Chen Z (2013) J Comput Chem 34:121-131

46 Miliordos E, Aprà E, Xantheas SS (2013) J Chem Phys 139:114302_1-114302_13

47 Shields RM, Temelso B, Archer KA, Morrell TE, Shields GC (2010) J Phys Chem A 114:11725 -11737

48 Fanourgakis GS, Aprà E, Xantheas SS (2004) J Chem Phys 121: 2655- 2663

49 Furtado JP, Rahalkar AP, Shanker S, Bandyopadhyay P, Gadre SR(2012) J Phys Chem Lett 3:2253-2258

50 Parkkinen P, Riikonen S, Halonen L (2013) J Phys Chem A 117:9985-9998

51 Mezei OD, Ruzsinszky A, Csonka GI (2016) J Chem Theory Comput 12:4222-4232

52 Kabrede H, Hentschke R (2003) J Phys Chem B 107:3914-3920

53 Takeuchi H (2008) J Chem Inf Model 48:2226-2233

54 Kirov MV, Fanourgakis GS, Xantheas SS (2008) Chem Phys Letters 461:180-188

55 Yoo S, Kirov MV, Xantheas SS (2009) J Am Chem Soc 131:7564-7566 
56 Willow SY, Xantheas SS (2012) Chem Phys Letters 525-526:13-18

57 Ramya KR, Venkatnathan A (2012) J Phys Chem A 116:7742-7745

58 Sloan ED, Koh C (2007) Clathrate Hydrates of Natural Gases. CRC Press, Taylor \& Francis Group 